Article

\title{
Analysis of the Impact of COVID-19 on the Food and Beverages Manufacturing Sector
}

\author{
Arnesh Telukdarie ${ }^{1, *}$, Megashnee Munsamy ${ }^{1}$ and Popopo Mohlala ${ }^{2}$ \\ 1 Postgraduate School of Engineering Management, University of Johannesburg, \\ Johannesburg 2006, Gauteng, South Africa; mmunsamy@uj.ac.za \\ 2 Food and Beverage Manufacturing Sector Education and Training Authority, \\ Johannesburg 2006, Gauteng, South Africa; PopopoM@FoodBev.co.za \\ * Correspondence: arnesht@uj.ac.za; Tel.: +27-61-450-5948
}

Received: 3 September 2020; Accepted: 20 October 2020; Published: 10 November 2020

check for updates

\begin{abstract}
The globe has been subjected to an unprecedented health challenge in the form of COVID-19, indiscriminately impacting the global economy, global supply chains, and nations. The resolution of this unprecedented challenge does not seem to be in the short-term horizon but rather something the globe has to live with. Initial data provides for some insights on responses, precautions, and sustainability protocols and processes. The Food and Beverages Manufacturing sector in South Africa (SA) and globally is an expeditious respondent to the COVID-19 challenge. Food is essential for human existence, but the food value chain is subjected to significant COVID-19 risks. The Food and Beverage Sector Education and Training Authority is responsible for skills development in the Food and Beverages (FoodBev) Manufacturing Sector in South Africa and seeks to quantify Foodbev sustainability. This research paper reviews global literature, performs a high-level knowledge classification, with the aim of expedited awareness, knowledge sharing, and most importantly, quantification of an expedited response, within the FoodBev Manufacturing sector in SA. The research is contextualized via a SA sector-based instrument deployment and data analysis. The paper provides insights into COVID-19 impact, adaptations, and responses in the SA Food and Beverages Manufacturing sector.
\end{abstract}

Keywords: COVID-19; food and beverage; manufacturing; sustainability

\section{Introduction}

In the context of the global economy, food is key to consumer confidence, global peace, and personal sustenance. Maintaining the movement of food through the global supply chain is essential for sustaining life. There is an overwhelming global response to the COVID-19 virus with Food and Beverage Sector sustainability a key challenge. As the Food and Beverages Manufacturing sector provides the essential service of food, a significant portion of businesses remained open in South Africa (SA) during the lockdown period with the exception of the alcohol manufacturers and distributors. However, there are disruptions to the global and local supply chain impacting the production of food. The COVID-19 response time and the knowledge base for preparing the sector in SA is fundamental.

The COVID-19 challenge faced by the Food and Beverages Manufacturing sector includes operations, safety, supply chain, training, emergency responses, awareness, incident management, recreating business models, digitalization, and other unanticipated impacts. Further to this, COVID-19 has changed consumer behavior to food. There are significant global and South Africa (SA)-specific impacts anticipated, with Small, Medium, and Micro Enterprises (SMME)'s expected to be significantly impacted. Thus, the short term and long-term impacts of COVID-19 on the South African Food and 
Beverages Manufacturing sector has to be determined to expedite recovery and to develop measures for readiness should another such disruption occur.

The SARS COVID-19 is categorized as a global pandemic [1], with almost 865,000 global deaths and 26 million infections, as of 3 September 2020 [2]. COVID-19 transmission occurs via contact and proximity, is carried on surfaces for up to nine days, and is destroyed via limited protocols such as alcohol, UV light, and 0.5\% sodium hypochlorite [3].

The Food and Beverages Manufacturing sector is in urgent need of an understanding the virus, from an operations perspective. The Food and Beverages Manufacturing sector has to institute health and safety protocols to respond to employee safety. Key additional considerations for the sector relates to operational constraints. The need to restructure operations so as to produce the relevant food products in a safe, financial, and environmentally sustainable manner.

The research team seeks to also identify catapult opportunities via this study. This research seeks to address the following questions:

- What is the global best practice in planning and responding to pandemics such as COVID-19?

- What are the impacts, both short term and long term, on the South African Food and Beverages Manufacturing sector?

- What are the recovery/mitigation measures required?

The high-level methodology of this study is mixed methods and includes a global peer reviewed literature search, a white paper search, compilation of benefit determination in SA, and an instrument to evaluate relevance and benefit in the SA Food and Beverages Manufacturing context. This research commences with a global scan of current knowledge, albeit not limited to peer reviewed publications. The objective is to rapidly gather relevant contextualized information. The research team build a South African (SA) data collection and response protocol based on this initial data collection cycle. The key knowledge themes are developed as the qualitative data is collected.

\subsection{Impact of COVID-19 on the Food and Beverages Manufacturing Sector Globally and in South Africa}

The research team adopt a multi-tier literature review approach that includes peer reviewed journals and conference papers together with a review of white papers from globally recognized entities. A Scopus search is conducted to commence publications analysis. Figure 1 illustrates the countries with the highest number of peer-reviewed COVID-19 publications, specific to the Food and Beverages Manufacturing sector. A total of 482 publications are identified, screened, and reviewed as a basis for this paper. In addition, a global best practice search is also conducted in order to find further papers on Food and Beverages Manufacturing and COVID-19.

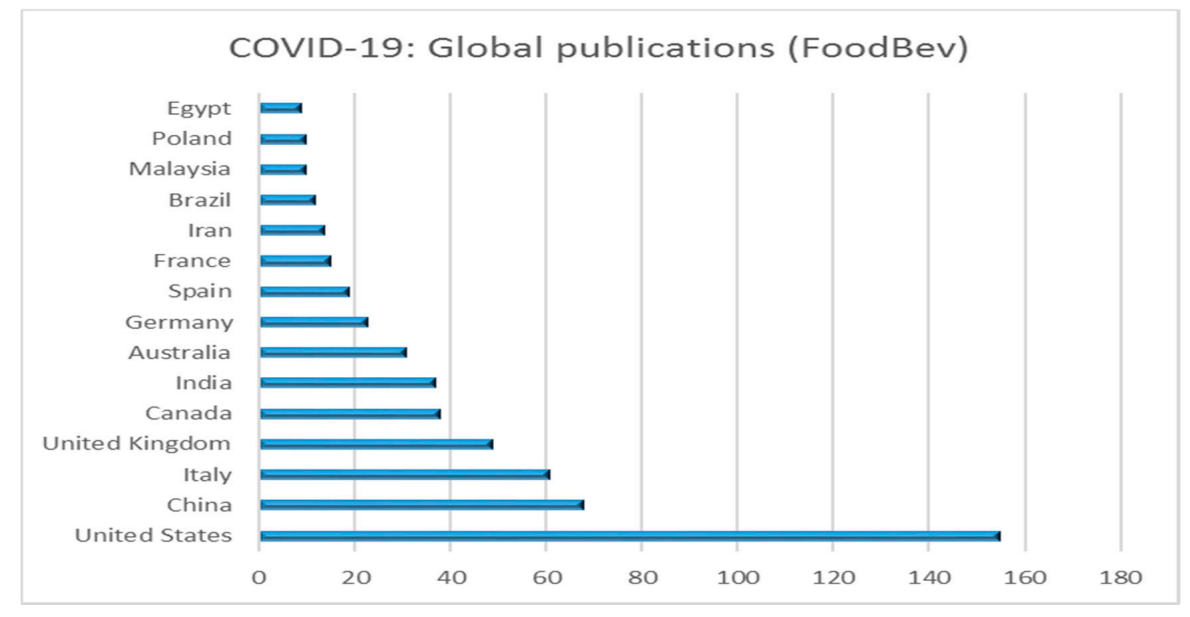

Figure 1. Number of publications per country. 
It is projected that the South African food and non-alcoholic beverages manufacturing is going through a moderate decline of flow of income $(-10 \%$ to $-30 \%)$, whereas the alcoholic beverages will experience a bigger impact at $-60 \%$ [4]. Further, Anderson et al. [5] argue the potential for significant interruption in the activities of the Food and Beverages Manufacturing sector cannot be ignored.

The varying levels of lockdown initiated in various countries globally, social distancing requirements and health concerns, have seen a shift in consumer behavior to home cooked meals rather than eating out [6]. Beef, which is used extensively in restaurants and fast food services, has experienced a significant decline in demand. Since the start of lockdown, an increased demand of snacks and baking goods was observed globally, as people were eating more during the day [7]. In Italy and China, changes in food patterns were observed with greater demand for staple, non-perishable foods and a reduction in demand for fresh fruit and demand [8]. This could lead to wastage due to limited shelf life and loss of income to farmers. Further, the high value commodities processing plants are labor intensive and maintaining of social distancing is difficult. The closure of restaurants, coffees shops, and farm-holiday stays resulted in a $10 \%$ reduction in milk consumption, a significant impact to the dairy industry [8]. In the international sphere the confectionary, snacks, other food products, baking, and grain mill industries have experienced an increase in demand of products and have been forced to operate on online platforms to meet the demand. However, the baking industry might experience challenges as lockdown continues. The executive director for the SA Baking Chamber reported that Tiger Brands closed one of their biggest firms during lockdown, but indicated that the supply of food remains stable. The company's profits have fallen by $75 \%$ (R359.6 million in 2020 vs. R1.4 billion in 2019) during the same time last year due to COVID-19 [9]. Demand for baked food could prove a challenge for food producers, especially producers of soft luxuries, as consumption is a function of income as well as certainty of income. The latter is a result of other people's financial status as they have lost their jobs and therefore do not have spending power. South Africa's alcoholic beverage industry has been hit hard by COVID-19 lockdown regulations, as the sale and export of alcohol is prohibited under the disaster regulations governing the national lockdown in South Africa [10]. Reports show that an estimated 117,600 jobs have been lost throughout the alcohol industry, $13 \%$ of the craft beer sector is in the process of shutting up shop, and the wine industry is in severe distress [11].

The suppliers of the Food and Beverages Manufacturers have also been impacted by COVID-19, influencing manufacturing operations. High value commodities of fresh fruit, vegetable, and fish are affected by the potential shortage of migrant seasonal labor for fruit picking, harvesting, etc. [8,12]. According to FAO [13], the fishing industry in many countries is considered critical for food production and supply; however, due to COVID-19, the fishing industry is facing two main problems of disrupted supply chain and declining markets, resulting in disruptions in transportation, trade, and labor. Disruptions in these lead to delayed stock and lower supplies, access, and consumption of these food [13]. Fish farmers who cannot sell the fish must now keep larger volumes of fish that need to be fed, increasing costs and risks [14]. The production of aquaculture may also be affected by the ability to purchase feed and seed due to cargo restrictions and prioritization [14]. Health safety measures of physical distancing and face masks can make fishing difficulty even to the point of reducing or stopping it [14]. If a crew member has the virus, it can easily spread to other members, and medical assistance may not be easily accessible due to being out at sea [13]. The reduced staff may result in a decline of Fisheries Monitoring and Control as observed during the 2013-2016 Ebola outbreak in West Africa [14]. This results in an increase in illicit activities and in a less responsible level of managing, monitoring, and controlling of fishing operations. The staple commodities of wheat, maize, corn, and soybean are capital intensive farming and could be affected by value chain disruptions due the requirements of various and large amounts of inputs such as seeds, fertilizers, pesticides, diesel, etc. [15]. This does not have a short-term impact but a long-term impact of food growth and availability for the following seasons/years. Restriction of movement and closure of markets have a significant impact on small holder producers, who do not have the finance and resources of larger producers [12]. A prolonged disruption could affect the ability to resume production [8]. 


\subsection{COVID-19 and Sustainability}

The lockdown enforced in various countries globally and the operational impacts of COVID-19 have had negative impacts on economies and severely impacted the sustainability of businesses. To stimulate economic recovery and towards business continuity, countries have initiated various measures, see Table 1, from financial stimulus packages to delay in loan repayments to waiver of loan fees to technology support. The measures introduced by a few countries are detailed below.

Table 1. Country specific COVID-19 responses.

\begin{tabular}{cc}
\hline Country & Response \\
\hline & $\begin{array}{c}\text { Alibaba, an e-commerce company, created an e-commerce platform to assist famers in selling } \\
\text { their unsold agricultural products and is also creating a "green channel" for fresh produce. } \\
\text { The Beijing central government set up a USD 20 million subsidy for purchasing of machines } \\
\text { and tools for agricultural purposes. It is also providing low interest rate loans and rent } \\
\text { reductions to incentivize development of digital agricultural technologies, such as } \\
\text { agricultural drones and unmanned vehicles. }\end{array}$ \\
China [15] & $\begin{array}{r}\text { The Agricultural Bank of China is reducing the interest rate by 0.5\% for small and medium } \\
\text { enterprises, self-employed, and private owners in the Hubei Province [8]. }\end{array}$ \\
\hline Italy [15] & $\begin{array}{r}\text { Allocated 100 million euros in support of agricultural and fishing businesses, which had to } \\
\text { halt operations. A further 100 million Euros is allocated for financing. } \\
\text { Permitting advance payments from the European Union subsidies to farmers. }\end{array}$ \\
\hline India [16] & $\begin{array}{r}\text { Implementing software for warehouse-based trading of harvested food to reduce congestion } \\
\text { at wholesale markets. }\end{array}$ \\
\hline Poland [16] & Offered subsidized loans to food processing businesses to facilitate continuous operations. \\
\hline
\end{tabular}

The diversification of business offerings from products and services to business supply chain influences the business ability to respond to business disruptions and uncertainties. Alcohol producers in the UK such as William Grant \& Sons and Diageo have begun producing hand sanitizers, whilst chemical company INEOS set up a hand sanitizer facility manufacturing one million bottles per month, which began production on 31 March 2020 [17]. A ventilator consortium was set up in the UK to address the need of increased demand. The consortium consisting of various businesses such as Airbus, BAE System, Microsoft, Accenture, Ford Motor Company, and Rolls-Royce announced on 2 April 2020 they are to produce 1500 ventilators per week based on the Penlon and Smiths design. The consortium is reported to have received an order for over 15,000 units from the UK government alone [17]. These businesses may not continue manufacturing the products post COVID-19, but it allowed the business to be operational and productive during a disruptive period.

A key consideration in business sustainability is environmental sustainability. The environmental impact of COVID-19 globally is initially quantified to be positive [18] due to reduced traffic, movement, air travel, and energy demand. Rugani and Caro [19] determined a 20\% reduction in carbon footprint in Italy for the months of March and April 2020 in comparison to the same months for the 2015-2019 period, an actual reduction between 5.6 and $10.6 \mathrm{Mt} \mathrm{CO}_{2} \mathrm{e}$.

However, there are concerns the post COVID-19 environmental impacts might be neglected in the drive to stimulate economic resurgence. Helm [18] states COVID-19 responses may result in significant post COVID-19 growth which could have a negative impact on climate change. Rosenbloom and Markard [20] state that the US may be revitalizing the fossil fuel industry via stimulus funding, whilst a report by the German Council of Economic Experts neglected to mention climate change or sustainability. However, 17 European climate and environment minsters requested a Green Deal be incorporated in the recovery plan. Rosenbloom and Markard [20] recommend the recovery plan include funds to support low carbon energy technologies/projects that reduce or mitigate carbon emissions such as renewable technologies, energy storage, and electric vehicle. They further recommend support and development of remote working, video conferencing, e-commerce, and reduced travel, whilst suggesting using the current destabilization of business and economies to accelerate transition 
towards clean options. Other considerations for climate change include the impact of elevated alcohol manufacture and application as a preventative measure as well as the impact of COVID-19 waste on the environment.

\subsection{COVID-19 Impact on Supply Chain}

COVID-19 has impacted all spheres of the global supply chain including distribution and packaging, as well as sourcing of raw materials [21,22]. Lockdowns disrupted the transportation of packaged foods, prepared foods, and non-alcoholic and alcoholic beverages [21], whilst some companies had to close for up to two weeks for cleaning purposes [15,23]. Weersink et al. [23] also identifies capacity constrains due to social distancing in the workplace leading to operational challenges. Operational challenges include the nature of packaging due to the reduced restaurant demand.

The disruption of the global supply chain has emphasized the risk of high probability external dependence on essential items. The economic stability of a country impacts its food security; the ability to manufacture or import the required food needs. Singapore, which imports a large amount of its food, plans to produce $30 \%$ of its food by 2030, in comparison to 2019 where it only produced $10 \%$ of its food needs [24]. Hossain [25] highlights various eastern block countries limitation of imports and exports on food products, including rice, poultry, eggs, vegetables, fish, and fruit. Gemmill-Herren [26] further identifies countries would procure food locally for various reasons, beyond the fact that imports have slowed down. Thailand, which depends heavily on tourism, approximately $20 \%$ of GDP, plans to diversify its economic sector through target industries of electronics, automotive, and chemicals, as its manufacturing sector already contributes $27 \%$ of its GDP [24].

Weersink et al. [23] also highlights central co-ordination bodies for farmers and distribution to be a priority. In Brazil, the existing Solidarity Purchasing Groups (GAS) and Community Supported Agriculture (CSA) exist as a network for farmers. This is an example of localized supply chain management, should localized networks be prioritized. Other strong examples of localized community coalitions are presented in North America and other parts of the world. Preiss [27] also identifies local supply networks.

The literature also indicates that a broader system of systems or ecosystem approach should be considered for workforce and supply chain; workforce ecosystems should include health and childcare as priorities while supply chains need to become dynamic and localized. The need to adopt a distributed global services model is recommended.

- Use a mixture of service models to de-risk the organization in a volatile world. Distributed global services mean that high performance can be delivered anytime, anywhere.

- Improvement of call centers and customer interaction.

- Augment and automate service: Virtual agents.

- Enhance virtual agent capabilities to support COVID-19 specific requests or growing Business as Usual volume.

- $\quad$ Alternative suppliers and distributors.

- Visibility of supply and demand network (digital).

\subsection{COVID-19 and Technology}

COVID-19 is forcing the development of resilient food systems [28]. Digital technologies can improve resiliency of food chains and assist in optimizing outputs [22,29]; 4IR technologies such as Big Data, Internet of Things (IoT), Cloud Computing, Robotics, and Automation facilitate remote and autonomous working whilst providing transparency in operations. Galanakis [30] reinforces various aspects of digital and 4IR, specific to benefits to the sector including supply chain optimization, and faster time to market. Preiss [27] identifies e-commerce platforms as a key to surviving COVID-19. These platforms are an opportunity in Brazil. Weersink et al. [23] identifies the process of automation 
to be accelerated at all levels of the supply chain in the Canadian food sector. Contactless delivery is becoming a norm from farm to store [23], requiring digital technologies.

Further consumers require more information about the products being purchased. Consumers are digitally savvy and smart devices deliver knowledge, provided for automation (personal data, searchers for choices, order management). Barcodes with embedded microscopic electronic devices such as Radio Frequency Identification (RFID) tags, genetic markers, and hyperspectral imaging used in conjunction with mobile phones would enable consumers to access information about the authenticity, freshness, ripeness, shelf life, and nutritional content of food [31]. Intelligent packaging is driving the growth of the packaging industry because it integrates an intelligent (communication) aspect to conventional packaging as it communicates information to the consumer in real-time as and when it senses, detects, or records any changes to the product [32]. Consumers are also seeking to adopt technology in advising on food to eat. This is specific to technologically centric personal analysis.

With social distancing requirements, remote working has increased, via the use of various platforms such as Zoom and Microsoft Teams, which further enhances resiliency; business can contact suppliers and customers and develop alternative collaborative solutions.

\subsection{Agile Workforce}

The COVID-19 pandemic has highlighted the need for a responsiveness workforce inclusive of management. It is clear that food and beverage companies must adopt to operate in a volatile, uncertain, and complex environment. Companies have to prepare for changes in operations; this includes a structured, specialized management response team as recommended by Accenture [33] (refer to Figure 2).



Figure 2. Management response timeframe (Adopted from Accenture [33].)

COVID-19 has also emphasized the need for an agile and elastic workforce [34]. Accenture [33] recommends the creation of an elastic digital workspace taskforce comprising of HR, legal, business, IT, marketing, sales, and communication representatives to oversee activities; a central command center. One of the most adopted techniques of an agile workforce is remote working, facilitated via collaboration platforms such as Zoom or Microsoft Teams. Accenture has identified six aspects requiring address to transition to a remote workspace [34]:

Culture and adoption: It is critical that the necessary tools, training, and coaching are provided. The use of online team meetings or videos: to keep staff aware of changes and the need for the change and demonstrations/trainings sessions on the use of the digital tools. The transition to cloud: for use of applications/software, creating and collaborating on documents and task management. It is also 
recommended to develop recommended/best practices for remote working, such as turning off video to improve audio in team meetings or workshops.

- Elastic collaboration: Expansion of communication and collaboration tools is required as more workers are remotely based. Ensure employees can use the designated communication and collaboration tools.

- Virtual work environment: Ensure employees have the tools and access to relevant applications and most especially data.

- Seamless networking: Ensure seamless connection to required business networks, cloud applications/services, and partner networks.

- Distributed continuity: Pandemic preparation must be merged into business plans. Keeping well-informed of developments and availability to make quick decisions and communication.

- Adaptive security: The mandatory security procedures are in place to decrease corporate risk and safety breaches. Develop and increase the usage of analytics and automation to reduce the amount of human intervention required.

The key is to develop a team that can respond quickly in an emergency situation [12]. This may form part of business continuity planning or can become a system centric approach. Other considerations for this strategy include the adoption of Artificial Intelligence (AI) [33], where the system is empowered via data and history to respond to the "threat."

Furthermore, in developing an agile and responsive workforce, food safety has to be inherent and inclusive of supply chains [35]. Food Safety Management Systems (FSMS) based on the Hazard Analysis and Critical Control Point (HACCP) principles must be put in place to manage food safety risks, and prevent and respond to food safety emergencies like outbreaks of foodborne diseases. Dyal et al. [36] highlights disinfecting of high touch areas, introducing outside break areas and adjusting start/stop and shift times. In developing the agile workforce and workspace, the following must be considered towards ensuring food safety:

- Reconfiguration of workplace: The workplace has to provide for social distancing. The number of people on site and within a defined confined space has to be reviewed.

- Worktime re-adjustment: Change in schedules, introducing shifts and other changes to worktimes has to be considered.

- Hazardous pay: The prioritization of categories of work based on risk has to be reviewed. Certain categories of workers would qualify for hazardous pay.

- Making remote working permanent: Staff that can work offsite should be contracted to do so. This should be encouraged with productivity measures in place. The impact on company real estate, onsite facilities, travel, and the environment should be additional considerations.

The literature also discusses the option of companies considering labor exchange. In principal, companies create a pool of labor that can be activated based on various business constrains. The key is to have a skilled labor force that can be interchangeably used based on worker health, demand, and other factors.

Additional Human Resources (HR) aspects have to change [36]. This includes the approach to sick leave. Rewarding sick leave would drive the wrong behavior. Additional sick leave, liability benefit which is not punitive.

\subsection{COVID-19 and Skills}

The Food and Beverages Manufacturing SETA's core mandate is skills development specific to the Food and Beverages Manufacturing sector. This research focuses on COVID-19 mitigation specifically via skills development for sustainability. The shape of skills training has changed globally especially with the onset of COVID-19. Various training mechanisms have to be addressed. 
The introduction of asynchronous (students learn the same content at different times) learning is a consideration, as not all learners need to be in the same classroom at the same time. Digital content distribution makes asynchronous learning a reality [37].

Latchem [38] highlights various tools that can be successfully used for skills development for post school learning; the book focuses on Technical and Vocational Education and Training (TVET). The following methods are discussed in detail: Virtual Reality; Mobile Learning; Simulations, Games and Role Plays; Augmented Reality; 3D Printing; Digital Repositories. The book provides insights into the work done in various countries globally. The use of Information and Communication Technologies (ICT) is highlighted as a driver to improve throughput with cost reductions and improved access. Latchem [38] also highlights the need to understand that a different approach is required for ICT-based learning, including:

- Discipline

- Pre-screening of students and basic skills development

- Hardware and data

- A structured mix of theory and practical is required

- Need to further train the SMME sector on the skills of ICT instructions

Latchem [38] identifies mixed time investment for learners as working well; this includes a $40 \%$ allocation by the companies employing the learners and $60 \%$ of learner's own time. Timely response mechanisms must be put in place, including verbal communication with learners. Verawardina [39] reinforces the need for structure in the learning cycle with roles and responsibilities as an additional highlight.

\section{Materials and Methods}

The aim of this study is to extract a SA specific response to COVID-19, based on current international trends. The research methodology adopted for this study is best described as mixed methods, comprising of qualitative data collection via a desktop literature review and a quantitative instrument deployment to gather relevant data, specific to the South African Food and Beverages Manufacturing context.

The initial aspects of the study include a global literature search, seeking response and impacts specific to the Food and Beverage manufacturing sector, and COVID-19. Based on the literature analysis, a structured data gathering instrument is developed and deployed in the SA Food and Beverages Manufacturing Sector. The instrument aligns to literature as extracted in the literature section.

Sampling considerations include the fact that the food and beverage sector in SA comprises some 11,000 companies, of which 93\% are SMME's and around 700 companies provide Work Skills Plans (WSP) to the Food and Manufacturing Sector Authority (SETA). The SETA databases are used to manage the data gathering processes. A statistically representative sample for the 11,000 members would be 184 , for a $95 \%$ confidence and $1 \%$ error.

The instrument is developed and with the knowledge of the literature categorized into sections, see Figure 3.

A thematic analysis is conducted based on the sector, company size, and province in which the company operates its business. The Cronbach Alpha reliability test is conducted on feedback data for each knowledge theme. The research team conduct thematic analysis on size of company, supply chain impacts, skills impact, and operational impacts and resources centric impacts. Long-term COVID-19 impact and sustainable responses to COVID-19 are extracted. 
General Information

-General information on the business, location, size, supply chain (local/Africa/ International)

\section{Business Impact of COVID-19}

-Business impact, COVID-19 impact on business, supply chain, environment, investments, digital, Automation and Robotics and Human resources.

\section{Mitigation Measures}

-Mitigation Measures: products, marketing, packaging, health and safety, and skills, future skills

\section{Skills development}

-Skills development, Training, skills mitigation, mixed methods and digital training.

Figure 3. Instrument categories and focus.

\section{Results}

\subsection{Statistical Analysis of Responses}

The overall validity of the study is tested based on the population and number of responses received. The team received 106 responses, which gives a 90\% confidence and an $8 \%$ error. The first tier of analysis conducted by the team relates to the data reliability tests. The Cronbach Alpha statistical test is adopted to test for reliability. Due to diversity of subject matter of questions, within the COVID-19 context, the questions are clustered bases on themes such as human resources, supply chain, training questions. The instrument is tested for reliability in sections and as per the instrument design. The following reliability tests are conducted with Cronbach Alpha results detailed in Table 2.

Table 2. Cronbach Alpha results.

\begin{tabular}{|c|c|c|c|}
\hline No. & Question Description & No. of Sub-Categories & Cronbach Alpha \\
\hline Q1 & $\begin{array}{l}\text { At this point in time, how is your business operation } \\
\text { being impacted by COVID- } 19 \text { and what is the level } \\
\text { of impact? }\end{array}$ & 11 & 0.76 \\
\hline Q5 & $\begin{array}{l}\text { Studies show that because of the unprecedented } \\
\text { measures being taken globally to attempt to limit the } \\
\text { spread of the virus, there have been significant } \\
\text { disruptions in food supply chains. What kind of } \\
\text { impact is COVID-19 having on supply chains of your } \\
\text { business operation? }\end{array}$ & 6 & 0.81 \\
\hline Q8 & $\begin{array}{l}\text { Q8: Is your company using or planning to use any of } \\
\text { the following online and/offline distance learning } \\
\text { tools for training: Online learning programs, video } \\
\text { conferencing, virtual reality simulators, } \\
\text { and multimedia. }\end{array}$ & 5 & 0.586 \\
\hline Q10 & $\begin{array}{l}\text { How is your company handling HR issues as they } \\
\text { relate to COVID-19? }\end{array}$ & 5 & 0.58 \\
\hline Q15 & $\begin{array}{l}\text { Businesses across the world have put in place a } \\
\text { variety of measures to help mitigate against the } \\
\text { impacts on their business. How has your company } \\
\text { responded to the COVID-19 outbreak? }\end{array}$ & 17 & 0.71 \\
\hline
\end{tabular}

The first tier of analysis conducted by the team relates to the data reliability. The Cronbach Alpha statistical test is adopted to test for reliability. Due to diversity of subject matter of questions, within the 
COVID-19 context, the questions are clustered based on themes such as HR, supply chain, training, impacts, and mitigations. The Instrument is tested for reliability in each of the clusters.

Questions 1, 5, 10, and 15 are defined as multi-category questions, as each question comprises an overarching question, with the response delineated to applicable themes. In Question 1, the companies rate the impact of operational challenges introduced by COVID-19. These challenges are identified from a global review of business challenges brought upon by COVID-19. A Cronbach Alpha of 0.76 is calculated indicating data reliability and that South African Food and Beverages Manufacturing companies (large, medium, micro, and small) are encountering similar operational challenges. It further indicates that SA Food and Beverages Manufacturing companies are experiencing similar challenges as their global counterparts.

Question 5 analyzes the impact to business supply chain, with the Cronbach Alpha calculated as 0.81 , indicating a strong reliability. This demonstrates that most companies are experiencing supply chain disruptions, both locally and internationally. This is one of the most significant challenges of businesses globally, given the closure of borders and businesses (due to lock downs).

Question 10 analyzes the business response to HR practices ranging from sick leave policies to COVID-19 response of screening, Personal Protective Equipment (PPE), etc. The Cronbach Alpha of 0.58 indicates some inconsistency. This inconsistency is further analyzed in this document.

Question 15 analyzes the response to 17 mitigation measures identified from a global review. A Cronbach Alpha of 0.71 is calculated indicating data reliability. This demonstrates that SA Food and $\mathrm{BEV}$ companies have already or are considering the mitigation measures, aligning to global trends in business recovery.

Questions 2 and 3 address climate concerns, thus they are analyzed together. A Cronbach Alpha of 0.51 is calculated indicating some inconsistency. This inconsistency is due to the disassociation between the questions. Most companies indicated no investment plans aligned to stimulus packages (Q2), but indicated future investment plans in environmental footprint reduction (Q3). The stimulus packages may present investment opportunities in new technologies and processes, which could simultaneously improve business performance and resiliency, while reducing environmental footprint.

Question 4 and 13 are clustered as it evaluates COVID-19 impact on business continuity. A Cronbach Alpha of 0.61 is calculated, indicating some data reliability. Whilst $86 \%$ of companies did not envisage closure of the business, 32\% identified the COVD-19 impact as severe. This contrasting data could attribute to the low Cronbach Alpha.

Questions 7 and 8 are clustered as it evaluates the current status of adoption of mixed methods in skills development/training. A Cronbach Alpha of 0.59 is calculated, indicating some inconsistency. Sixty-one percent of companies responded to having already adopted some form of mixed methods in their training programs (Q7). However, in evaluation of the specific mixed methods adopted (Q8), inconsistency is observed; $61 \%$ state have already adopted video conferencing, $27 \%$ each have adopted online learning and multimedia, and $12 \%$ have already adopted virtual reality simulator. The inconsistency in the Cronbach Alpha could potentially be attributed to the low adoption levels of online learning, multimedia, and virtual reality simulators.

\subsection{Data Analysis}

The research team provides an analysis of the overall response prior to sectional, theme, and individual questions analysis. The FB sector covers all nine provinces in SA, which comprises Small, Medium, and Micro enterprises (SMME) and comprises various sectors. An initial analysis is conducted, see Table 3.

The company distribution provides for data on representation and where necessary is used in the sectional, themed, and individual analysis. 
Table 3. Provincial/Category/Company size classification.

\begin{tabular}{cccccc}
\hline Row Labels & Companies & $\begin{array}{c}\text { Operating } \\
\text { Provinces }\end{array}$ & $\begin{array}{c}\text { No. of } \\
\text { Companies }\end{array}$ & Business Sector & $\begin{array}{c}\text { No. of } \\
\text { Companies }\end{array}$ \\
\hline Large & 28 & Northern Cape & 8 & Fish & 8 \\
Medium & 41 & Free State & 16 & Fruits \& vegetables & 17 \\
Micro & 9 & Eastern Cape & 20 & Meat & 16 \\
Small & 27 & Gauteng & 45 & Baking & 16 \\
Grand Total & 105 & Limpopo & 17 & Oil \& fats & 6 \\
& & North West & 11 & Grain Mill & 4 \\
& & KwaZulu Natal & 38 & Soft drinks \& water & 17 \\
& Western Cape & 50 & Beer \& Malt & 13 \\
& Mpumalanga & 11 & Other food products & 34 \\
\end{tabular}

3.2.1. Overall Analysis of Impact of COVID-19 on Food and Beverage Manufacturing Sector Businesses

A key screening question reveals that 12 of the 106 companies could close in the next 12 months. Table 4 below provides data relating to size of companies. It is apparent that smaller companies are being impacted with no large companies envisaging closure. The data on category of companies is not clear but of these 12 companies, 6 are from the "meat" category (a total of 16 meat companies responded). The exact driver for such a large representation in the meat category is beyond this study analysis.

Table 4. Business closure timelines.

\begin{tabular}{cccc}
\hline Closure Timeline & No. of Companies & Small & Medium \\
\hline 1 Month & 1 & & 1 \\
\hline 3 Months & 5 & 4 & 1 \\
\hline 6 Months & 4 & 2 & 2 \\
\hline 12 Months & 2 & 1 & 1 \\
\hline
\end{tabular}

The research team sought to reinforce data beyond the current perspective with a question on forecasting. At present, the long-term impacts of COVID-19 are uncertain, but the ramification will continue to be felt even after the spread of the virus is contained. What will be the impact for the future?

With 30\% of the companies electing not to answer, five percent felt there would be no impact in the future while the remaining $65 \%$ of the companies are envisaging future impacts.

The research now focuses on the operational impact of COVID-19 on Food and Beverage Manufacturing companies. Various literature sources provide inputs from a complete shutdown of business, adjusting work hours, impacts on sales and orders, business credit, reduced/increases in selected product lines, employee wellness, and administrative challenges. These are incorporated into a business impact question with a Low/Medium/High impact as feedback from companies. The data (Table 5) clearly indicate that there has been a high impact on small and micro enterprises in all categories. Large and medium companies have experienced low impacts. 
Table 5. Analysis of COVID-19 impacts on business operations.

\begin{tabular}{|c|c|c|c|c|c|c|c|c|c|c|c|c|}
\hline & \multicolumn{3}{|c|}{ Large } & \multicolumn{3}{|c|}{ Medium } & \multicolumn{3}{|c|}{ Micro } & \multicolumn{3}{|c|}{ Small } \\
\hline & Low & Medium & High & Low & Medium & High & Low & Medium & High & Low & Medium & High \\
\hline $\begin{array}{l}\text { We have completely closed our physical place of } \\
\text { business }\end{array}$ & $46 \%$ & $7 \%$ & $7 \%$ & $32 \%$ & $5 \%$ & $5 \%$ & $0 \%$ & $11 \%$ & $22 \%$ & $30 \%$ & $22 \%$ & $26 \%$ \\
\hline We have adjusted our hours of operation & $25 \%$ & $25 \%$ & $7 \%$ & $17 \%$ & $17 \%$ & $5 \%$ & $0 \%$ & $11 \%$ & $22 \%$ & $30 \%$ & $15 \%$ & $33 \%$ \\
\hline Temporary shutdown & $39 \%$ & $14 \%$ & $4 \%$ & $27 \%$ & $10 \%$ & $2 \%$ & $0 \%$ & $11 \%$ & $11 \%$ & $52 \%$ & $15 \%$ & $15 \%$ \\
\hline Orders are being cancelled & $43 \%$ & $14 \%$ & $0 \%$ & $29 \%$ & $10 \%$ & $0 \%$ & $0 \%$ & $0 \%$ & $33 \%$ & $37 \%$ & $11 \%$ & $30 \%$ \\
\hline Our supply chain is interrupted & $25 \%$ & $25 \%$ & $7 \%$ & $24 \%$ & $10 \%$ & $32 \%$ & $0 \%$ & $0 \%$ & $33 \%$ & $30 \%$ & $19 \%$ & $30 \%$ \\
\hline We are experiencing decreases in sales & $18 \%$ & $36 \%$ & $4 \%$ & $20 \%$ & $15 \%$ & $34 \%$ & $0 \%$ & $0 \%$ & $33 \%$ & $26 \%$ & $15 \%$ & $41 \%$ \\
\hline Employee absence due to sickness & $29 \%$ & $25 \%$ & $7 \%$ & $32 \%$ & $22 \%$ & $15 \%$ & $22 \%$ & $0 \%$ & $11 \%$ & $41 \%$ & $33 \%$ & $4 \%$ \\
\hline Reduced logistics services & $18 \%$ & $39 \%$ & $0 \%$ & $20 \%$ & $24 \%$ & $22 \%$ & $0 \%$ & $0 \%$ & $33 \%$ & $30 \%$ & $37 \%$ & $15 \%$ \\
\hline The market is causing us to draw our line of credit & $39 \%$ & $7 \%$ & $11 \%$ & $22 \%$ & $12 \%$ & $29 \%$ & $0 \%$ & $0 \%$ & $22 \%$ & $30 \%$ & $19 \%$ & $30 \%$ \\
\hline Increased administrative bottlenecks & $18 \%$ & $21 \%$ & $18 \%$ & $20 \%$ & $17 \%$ & $32 \%$ & $11 \%$ & $11 \%$ & $11 \%$ & $26 \%$ & $37 \%$ & $19 \%$ \\
\hline $\begin{array}{l}\text { We are experiencing increases in consumer } \\
\text { demand for certain products }\end{array}$ & $25 \%$ & $7 \%$ & $25 \%$ & $27 \%$ & $17 \%$ & $24 \%$ & $22 \%$ & $0 \%$ & $0 \%$ & $52 \%$ & $19 \%$ & $7 \%$ \\
\hline
\end{tabular}


The data on complete shutdown of business indicates a higher impact on small and micro businesses with large and medium experiencing at least $20 \%$ of businesses with a high impact. Essentially 1 in 5 small/micro businesses have been physically closed with a high impact. The adjustment of work hours has had a high impact on small and micro with a low impact on large business. Order cancellations are having a high impact on small business with very little impact on medium to large business. A decrease in sales impacts all but large businesses. Reduced logistics services is a high impact challenge across all sizes of business. Finance and line of credit have been used by medium/small/micro businesses and has a high impact. Small businesses indicate an increase in administrative bottleneck, this cannot be internal. It may be external with unemployment insurance and other government dependent activity.

\subsubsection{Supply Chain and FB Manufacturing}

The initial analysis is conducted on the supply chain as a key theme; the literature section of this paper provides details on supply chain disruptions.

With the onset of COVID-19, international trends are that supply chains are challenged. An analysis is conducted/size of respondents. With reference to Figure 4, it is very apparent that most companies (in excess of $80 \%$ ) source locally, with smaller companies more dependent on local supply than larger. On the outbound side, domestic is favored by smaller companies with larger companies conducting significant international trade. The African Region is the smallest focus both on inbound and outbound.

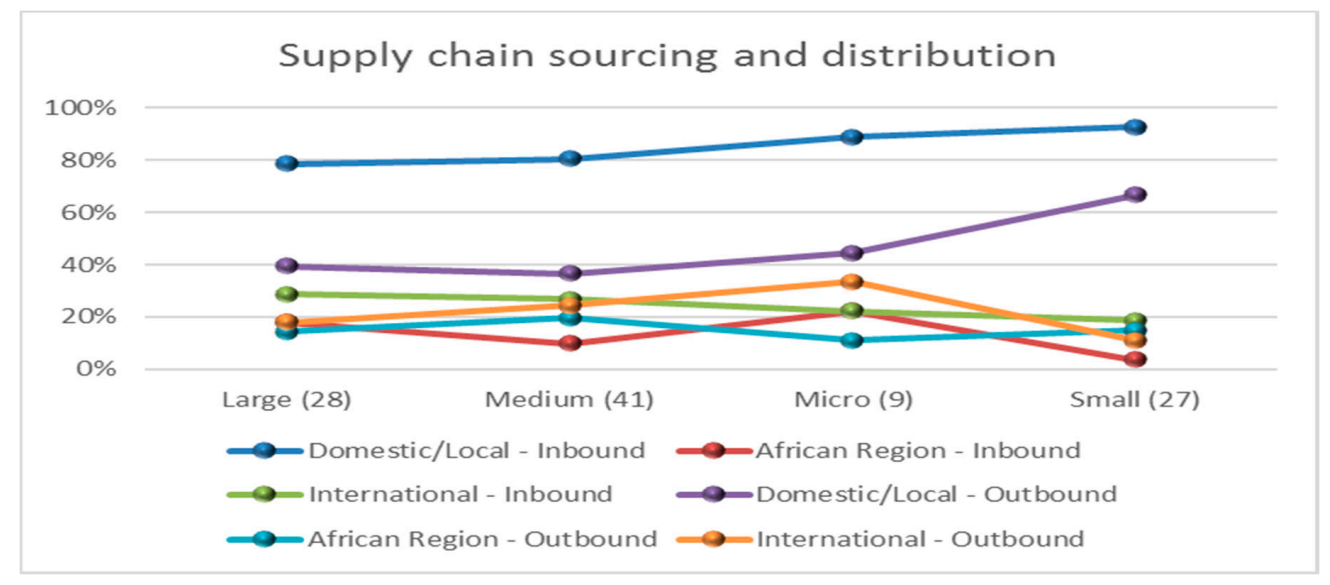

Figure 4. Analysis of impact on inbound and outbound network.

The research team added a question on if companies, due to COVID-19, sought to join SA sourcing and distribution networks and $50 \%$ of the current responders indicate that they currently source outside of SA and are looking at transitioning to SA sourcing. Data on supply chain is further reinforced by Section B/Business Impact. Question 1: What is the level of impact:

- Our supply chain is interrupted.

- Reduced Logistics services.

The results indicate that the combined medium to high impact in all sizes of business ranged from $36 \%$ to $50 \%$. This indicates the impact of COVID-19 on supply chain and logistics to be a challenge in the SA context.

\subsubsection{Business Impact: Question 5}

The data (Table 6) indicates clear challenges in lower domestic sales to customers and businesses, with medium to high impact on all business sizes. Accessing materials and goods internationally is also a challenge to business. It is also apparent that small businesses experience the most significant impacts on supply chain and sourcing and distribution. Further data probing on supply chain is conducted by the questions. 
Table 6. Analysis of impact on supply chain network.

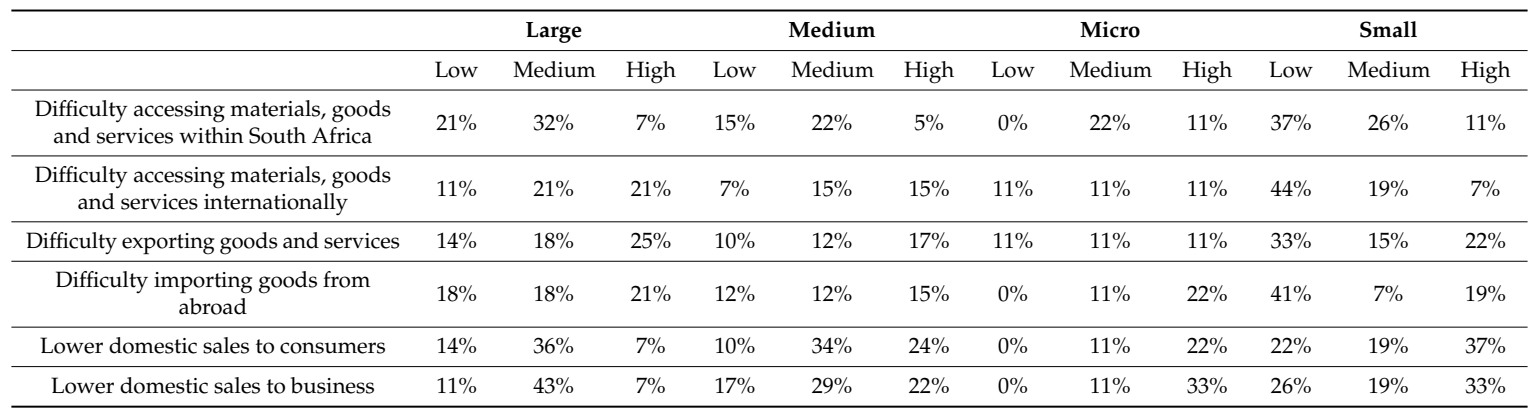

Regions and countries globally are preparing to improve supply chain via locally co-ordination. Does the company plan to institute or participate in a centrally coordinated (This may be on a provincial/ National level)? Yes/no

Research shows that COVID-19 has put a renewed urgency behind automation and the use of robotics to mitigate against the disruptive impact of supply chain. Is digitalization a consideration in local digital networks? Yes/no

The data, Table 6 , indicates that $58 \%$ of large companies are considering a centrally coordinated supply chain network, either at a local or national level. Only $27 \%$ of medium size and $26 \%$ of small companies are considering a centrally coordinated supply chain network. A similar trend is observed in the evaluation of adoption of digital supply chain networks, with medium and small companies demonstrating lower consideration of adoption, whilst large companies (63\%) are strongly in support of digital supply networks.

\subsubsection{Company Resource Based Mitigation}

A key resource at every company, small or large, are the employees. In this period of COVID-19, companies have to take care of this important resource. Best practice literature provides for responses in HR practices, leave, and healthcare, a dedicated COVID-19 HR team, dedicated risk teams, and communication around COVID-19. This is tested with SA Food and Beverage Manufacturing companies and $80 \%$ upwards responded that this is already done or being considered with $100 \%$ of companies having risk teams and improved COVID-19 communications.

In order to understand company specific mitigation action, the team tests international best practices, as extracted from literature. The key aspects tested includes product management, pricing, staff skills, reviewing planned upgrades, remote work, closure, packaging and online sales, refer to Table 7. Analysis of the FB data indicates four key categories that FB companies have already actioned. These include:

- $\quad$ Adjusting marketing strategies

- Upskilling staff

- Emergency response teams

- New health and Safety Protocols

- Changes in packaging is not a priority of FB business and nether is investing in upgrades.

There is a shift to online sales in all company sizes especially in small business. 
Table 7. Analysis of mitigation measures.

\begin{tabular}{|c|c|c|c|c|c|c|c|c|c|c|c|c|c|c|c|c|c|c|c|c|c|c|c|c|}
\hline & \multicolumn{6}{|c|}{ Large } & \multicolumn{6}{|c|}{ Medium } & \multicolumn{6}{|c|}{ Micro } & \multicolumn{6}{|c|}{ Small } \\
\hline &  &  & 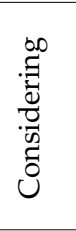 & 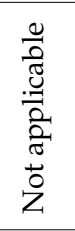 & 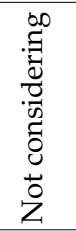 &  &  & 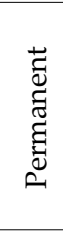 &  & $\begin{array}{l}\frac{0}{0} \\
\frac{0}{0} \\
: \frac{0}{2} \\
\frac{2}{0} \\
0 \\
0 \\
z \\
z\end{array}$ & 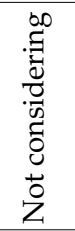 &  & 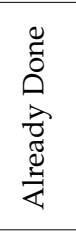 &  & 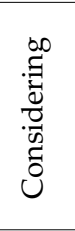 & $\begin{array}{l}\frac{0}{0} \\
\frac{0}{0} \\
: \frac{0}{0} \\
\frac{0}{0} \\
\frac{0}{0} \\
\text { z }\end{array}$ & $\begin{array}{l}60 \\
.0 \\
0 \\
0 \\
0 \\
0 \\
0 \\
0 \\
0 \\
0 \\
Z\end{array}$ & 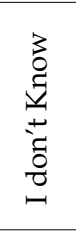 & 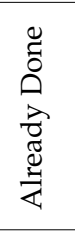 & 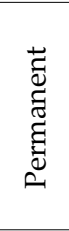 & 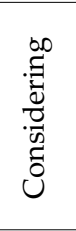 & $\begin{array}{l}\frac{0}{0} \\
\frac{0}{0} \\
: \frac{0}{0} \\
\frac{0}{0} \\
0 \\
0 \\
z\end{array}$ & 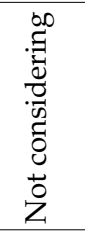 & 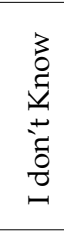 \\
\hline Introdu & $11 \%$ & $0 \%$ & $11 \%$ & $11 \%$ & $21 \%$ & $0 \%$ & $22 \%$ & $0 \%$ & $5 \%$ & $20 \%$ & $24 \%$ & $2 \%$ & $33 \%$ & $0 \%$ & $0 \%$ & $0 \%$ & $0 \%$ & $0 \%$ & $11 \%$ & $0 \%$ & $15 \%$ & $37 \%$ & $15 \%$ & $0 \%$ \\
\hline Offe & $14 \%$ & $0 \%$ & $7 \%$ & $7 \%$ & $14 \%$ & $11 \%$ & $22 \%$ & $0 \%$ & $20 \%$ & $7 \%$ & $20 \%$ & $2 \%$ & $0 \%$ & $0 \%$ & $0 \%$ & $0 \%$ & $22 \%$ & $11 \%$ & $19 \%$ & $0 \%$ & $7 \%$ & $15 \%$ & $33 \%$ & $4 \%$ \\
\hline Adjusted marketing strategie & $25 \%$ & $0 \%$ & $18 \%$ & $0 \%$ & $7 \%$ & $4 \%$ & $37 \%$ & $0 \%$ & $24 \%$ & $0 \%$ & $12 \%$ & $0 \%$ & $22 \%$ & $0 \%$ & $11 \%$ & $0 \%$ & $11 \%$ & $0 \%$ & $37 \%$ & $0 \%$ & $33 \%$ & $7 \%$ & $0 \%$ & $0 \%$ \\
\hline Upskilling staff & $21 \%$ & $4 \%$ & $21 \%$ & $0 \%$ & $7 \%$ & $0 \%$ & $24 \%$ & $2 \%$ & $27 \%$ & $10 \%$ & $7 \%$ & $0 \%$ & $22 \%$ & $0 \%$ & $11 \%$ & $11 \%$ & $0 \%$ & $0 \%$ & $26 \%$ & $0 \%$ & $26 \%$ & $19 \%$ & $11 \%$ & $0 \%$ \\
\hline Emergency response teams & $46 \%$ & $0 \%$ & $4 \%$ & $4 \%$ & $0 \%$ & $0 \%$ & $37 \%$ & $0 \%$ & $17 \%$ & $5 \%$ & $12 \%$ & $0 \%$ & $0 \%$ & $0 \%$ & $22 \%$ & $11 \%$ & $0 \%$ & $0 \%$ & $44 \%$ & $0 \%$ & $19 \%$ & $7 \%$ & $4 \%$ & $7 \%$ \\
\hline $\begin{array}{l}\text { New health } \\
\text { prot }\end{array}$ & $7 \%$ & $0 \%$ & $0 \%$ & $0 \%$ & $0 \%$ & $0 \%$ & $63 \%$ & $5 \%$ & $5 \%$ & $0 \%$ & $0 \%$ & $0 \%$ & $44 \%$ & $0 \%$ & $0 \%$ & $0 \%$ & $0 \%$ & $0 \%$ & $67 \%$ & $0 \%$ & $15 \%$ & $0 \%$ & $0 \%$ & $0 \%$ \\
\hline $\begin{array}{c}\text { Customer experience } \\
\text { improvements (call centres) }\end{array}$ & $25 \%$ & $0 \%$ & $4 \%$ & $4 \%$ & $11 \%$ & $7 \%$ & $22 \%$ & $0 \%$ & $15 \%$ & $22 \%$ & $12 \%$ & $0 \%$ & $11 \%$ & $0 \%$ & $11 \%$ & $11 \%$ & $0 \%$ & $0 \%$ & $15 \%$ & $0 \%$ & $11 \%$ & $26 \%$ & $22 \%$ & $0 \%$ \\
\hline $\begin{array}{l}\text { Cancel } \\
\text { expans }\end{array}$ & $7 \%$ & $0 \%$ & $4 \%$ & $14 \%$ & $25 \%$ & $4 \%$ & $29 \%$ & $0 \%$ & $22 \%$ & $5 \%$ & $15 \%$ & $0 \%$ & $33 \%$ & $0 \%$ & $0 \%$ & $0 \%$ & $0 \%$ & $0 \%$ & $30 \%$ & $0 \%$ & $15 \%$ & $15 \%$ & $15 \%$ & $0 \%$ \\
\hline Sourcing from new suppliers & $11 \%$ & $0 \%$ & $14 \%$ & $14 \%$ & $11 \%$ & $4 \%$ & $22 \%$ & $0 \%$ & $27 \%$ & $5 \%$ & $15 \%$ & 政 & $11 \%$ & 07 & $11 \%$ & $11 \%$ & $0 \%$ & 0 & $7^{\circ}$ & $\%$ & $37 \%$ & $15 \%$ & $15 \%$ & $0 \%$ \\
\hline Online sales & $21 \%$ & $0 \%$ & $21 \%$ & $7 \%$ & $4 \%$ & $0 \%$ & $22 \%$ & $0 \%$ & $15 \%$ & $20 \%$ & $15 \%$ & $0 \%$ & $33 \%$ & $0 \%$ & $0 \%$ & $0 \%$ & $0 \%$ & $0 \%$ & $33 \%$ & $0 \%$ & $22 \%$ & $11 \%$ & $11 \%$ & $0 \%$ \\
\hline Remote work & $36 \%$ & $0 \%$ & $14 \%$ & $0 \%$ & $7 \%$ & $0 \%$ & $22 \%$ & $0 \%$ & $17 \%$ & $17 \%$ & $17 \%$ & $0 \%$ & $33 \%$ & $0 \%$ & $0 \%$ & $0 \%$ & $0 \%$ & $0 \%$ & $19 \%$ & $0 \%$ & $19 \%$ & $19 \%$ & $26 \%$ & $0 \%$ \\
\hline $\begin{array}{l}\text { Investing in upgrades, } \\
\text { renovations or business } \\
\text { improvements }\end{array}$ & $11 \%$ & $0 \%$ & $29 \%$ & $4 \%$ & $4 \%$ & $4 \%$ & $12 \%$ & $0 \%$ & $27 \%$ & $10 \%$ & $20 \%$ & $2 \%$ & $11 \%$ & $0 \%$ & $11 \%$ & $0 \%$ & $11 \%$ & $0 \%$ & $7 \%$ & $0 \%$ & $15 \%$ & $15 \%$ & $37 \%$ & $0 \%$ \\
\hline Significant downscaling & $0 \%$ & $0 \%$ & $11 \%$ & $11 \%$ & $32 \%$ & $0 \%$ & $5 \%$ & $0 \%$ & $27 \%$ & $12 \%$ & $27 \%$ & $0 \%$ & $22 \%$ & $0 \%$ & $11 \%$ & $0 \%$ & $0 \%$ & $0 \%$ & $19 \%$ & $0 \%$ & $19 \%$ & $11 \%$ & $26 \%$ & $0 \%$ \\
\hline Temporary closure & $0 \%$ & $4 \%$ & $0 \%$ & $21 \%$ & $29 \%$ & $0 \%$ & $10 \%$ & $0 \%$ & $10 \%$ & $12 \%$ & $37 \%$ & $2 \%$ & $11 \%$ & $0 \%$ & $11 \%$ & $0 \%$ & $11 \%$ & $0 \%$ & $11 \%$ & $0 \%$ & $11 \%$ & $15 \%$ & $41 \%$ & $0 \%$ \\
\hline Permanent closure & $0 \%$ & $0 \%$ & $0 \%$ & $25 \%$ & $25 \%$ & $4 \%$ & $0 \%$ & $0 \%$ & $5 \%$ & $12 \%$ & $41 \%$ & $5 \%$ & $11 \%$ & $0 \%$ & $0 \%$ & $0 \%$ & $11 \%$ & $0 \%$ & $4 \%$ & $0 \%$ & $11 \%$ & $15 \%$ & $37 \%$ & $7 \%$ \\
\hline Changes in packaging & $4 \%$ & $0 \%$ & $21 \%$ & $11 \%$ & $11 \%$ & $7 \%$ & $10 \%$ & $0 \%$ & $20 \%$ & $10 \%$ & $29 \%$ & $0 \%$ & $11 \%$ & $0 \%$ & $0 \%$ & $11 \%$ & $11 \%$ & $0 \%$ & $0 \%$ & $4 \%$ & $33 \%$ & $11 \%$ & $26 \%$ & $0 \%$ \\
\hline
\end{tabular}




\subsubsection{Technology}

Literature indicates that the drive to mitigate risk to humans can be managed via digital or automation. The assessment of automation is tested in the SA context. Companies are requested to respond to digital supply networks and only the larger companies respond positively at $63 \%$ are in support of digital supply chain networks. Training in automation secures a low response rate from companies. Using digital for training has a significantly positive response, as detailed in the training section of this paper.

\subsubsection{Climate Change}

With the onset of COVID-19, research points to similar events due to the state of global climate, specifically associating health to climate change. Global indications are that due to stimulus packages and reduced costs of borrowing, companies find investment opportunities in COVID-19. Companies are tested with opportunity based on COVID-19 to respond to climate change. Seventy-five percent of SA companies don't find COVID-19 to be an opportunity. Companies do marginally find the need to optimize future investments based on climate; this is at $52 \%$ of companies.

\subsubsection{Resources Planning}

The research team explores the potential for current actions and changes becoming permanent via the question below. Which of the following do you anticipate becoming a permanent feature in your company post COVID-19?

The results are summarized in Table 8. Companies strongly support social distancing, transparency, and reconfiguration of the workplace.

Table 8. Analysis of potential new workplace practices.

\begin{tabular}{cc}
\hline Permanent Feature & Percentage Response \\
\hline Elastic workforce (shared workforce) & $14 \%$ \\
Healthcare benefits and management & $19 \%$ \\
Reallocating workforce to meet business demands & $20 \%$ \\
Employees working from home & $23 \%$ \\
Collaboration & $25 \%$ \\
Programs to encourage virtual working & $25 \%$ \\
Reconfiguration of facilities to mitigate COVID-19 spread & $34 \%$ \\
Increased communication and transparency & $44 \%$ \\
Social distancing at work & $55 \%$ \\
\hline
\end{tabular}

The research team focuses on training as a key aspect of data gathering in order to strategize on the FoodBev Manufacturing SETA's response to COVID-19. An initial assessment of the respondents is conducted to establish if companies are recipients of grants. Of the total sample, around $70 \%$ of companies responded to the Food and Beverages Manufacturing SETA 2020 grant call.

\subsubsection{Training}

The first set of questions probe companies' stipend support and continuation of training (Q1/Q2/Q4). The data in Table 9 demonstrates that large and medium companies are better resourced to continue with training during adverse business conditions. Large companies demonstrated higher capacity in payment of stipends, as compared to small and medium companies. Training investments in large and medium companies would enable the SETA to achieve training targets. 
Table 9. Summary of training registration and stipends numbers.

\begin{tabular}{ccccccccc}
\hline & \multicolumn{2}{c}{ Large } & \multicolumn{2}{c}{ Medium } & \multicolumn{2}{c}{ Micro } & \multicolumn{2}{c}{ Small } \\
\hline & No & Yes & No & Yes & No & Yes & No & Yes \\
\hline $\begin{array}{c}\text { Does your company have learners registered } \\
\text { for training? }\end{array}$ & $1 \%$ & $25 \%$ & $15 \%$ & $22 \%$ & $1 \%$ & $4 \%$ & $17 \%$ & $14 \%$ \\
\hline $\begin{array}{c}\text { Has the company continued training } \\
\text { learners during the lockdown period? }\end{array}$ & $8 \%$ & $17 \%$ & $27 \%$ & $11 \%$ & $4 \%$ & $1 \%$ & $20 \%$ & $11 \%$ \\
\hline $\begin{array}{c}\text { Does your company continue to pay } \\
\text { stipends to learners during the lockdown? }\end{array}$ & $0 \%$ & $37 \%$ & $12 \%$ & $24 \%$ & $2 \%$ & $7 \%$ & $2 \%$ & $15 \%$ \\
\hline
\end{tabular}

The next set of questions probes the completion time of the training and the types of training offered (Q3/Q6). In the short-term period of one to three months, the large companies are more disposed to complete the training programs. From the 6-month period, the potential of medium companies completing training substantially increases, with most small companies requiring 12 months. Learnerships, both employed and unemployed, represent $58 \%$ of all training programs offered, with internships at $28 \%$ and apprenticeships at $13 \%$.

Q11: Envisaged reductions in investments in training and development. Fifty-five percent of all companies responded that a reduction in training investment is anticipated due to the financial challenges being experienced. The $55 \%$ comprises $22 \%$ of medium companies, $20 \%$ of small companies, and $10 \%$ of large companies. This implies that medium and small companies are more financially constrained than large companies.

Q7 and Q8: The data indicates $83 \%$ of all companies are adopting or planning to adopt a mixed methods approach to skills training. The most commonly adopted tool across all company sizes is video conferencing, followed by online learning programs and resources such as Google classroom (refer to Figure 5. The planned priority methods for adoptions are online learning programs and resources, multimedia including podcasts, and YouTube and virtual reality simulators, respectively, refer to Figure 5.



Figure 5. Analysis of current and planned mixed methods for training. 
Q9: Challenges experienced by companies and mitigation measures. Ninety-five percent of all companies encountered challenges in continuation of training; with medium sized companies experiencing the most challenges, followed by small and large companies respectively. The critical factors impeding continuity of training across all company sizes in descending order of impact are illustrated in Table 10 and include infrastructure (internet connections, computer resources, etc.), limited digital literacy/skills of users, financial issues, and lack of adapted training programs.

Table 10. Factors impeding continuation of skills training.

\begin{tabular}{ccccc}
\hline & Large & Medium & Micro & Small \\
\hline Limited digital literacy/skills of users & $6.06 \%$ & $9.85 \%$ & $0.76 \%$ & $9.09 \%$ \\
\hline Financial constraints & $3.03 \%$ & $9.09 \%$ & $1.52 \%$ & $10.61 \%$ \\
\hline Lack of adapted training programs and resources & $5.30 \%$ & $7.58 \%$ & $1.52 \%$ & $4.55 \%$ \\
\hline Infrastructure issues & $10.61 \%$ & $10.61 \%$ & $2.27 \%$ & $7.58 \%$ \\
\hline
\end{tabular}

Table 11 illustrates the factors facilitating mixed methods skills development. The companies identified pre-training/online training as the most critical mitigation measure, followed by providing infrastructure as part of our service and investing in program adaption. Providing financial support and providing data were identified as the least important mitigation measures in ensuring continuity of training.

Table 11. Factors facilitating mixed methods skills training.

\begin{tabular}{ccccc}
\hline & Large & Medium & Micro & Small \\
\hline Pre-training/online training & $14 \%$ & $9 \%$ & $3 \%$ & $6 \%$ \\
\hline Providing financial support & $1 \%$ & $6 \%$ & $0 \%$ & $4 \%$ \\
\hline Investing in program adaption & $6 \%$ & $6 \%$ & $1 \%$ & $3 \%$ \\
\hline Providing infrastructure as part of our services & $11 \%$ & $10 \%$ & $1 \%$ & $4 \%$ \\
\hline Providing data & $8 \%$ & $4 \%$ & $0 \%$ & $3 \%$ \\
\hline
\end{tabular}

Q12: The final question to companies was on the envisaged areas requiring a change in training. The data identified safety, health, and HR as priority areas across all company sizes. This is in line with current regulations which requires companies to align to social distancing and safety practices at the workplace. Analysis, see Table 12, at the company size level indicates the following training areas as priority:

- Large companies: Categorizes all training areas as important.

- Medium companies: Health, HR, and safety, respectively.

- Small companies: Safety, health, and planning, respectively

Table 12. Business areas requiring training changes.

\begin{tabular}{ccccc}
\hline & Large & Medium & Micro & Small \\
\hline HR & $15 \%$ & $17 \%$ & $6 \%$ & $14 \%$ \\
\hline Supply Chain & $14 \%$ & $13 \%$ & $17 \%$ & $10 \%$ \\
\hline Safety & $15 \%$ & $16 \%$ & $17 \%$ & $20 \%$ \\
\hline Health & $15 \%$ & $18 \%$ & $17 \%$ & $18 \%$ \\
\hline Planning & $14 \%$ & $14 \%$ & $11 \%$ & $15 \%$ \\
\hline Automation/Digitalisation & $14 \%$ & $12 \%$ & $17 \%$ & $9 \%$ \\
\hline Research and Development & $15 \%$ & $10 \%$ & $17 \%$ & $14 \%$ \\
\hline
\end{tabular}


The COVID-19 pandemic has significantly changed the face of business and training. It is apparent that major changes in training, with a shift to digital, is planned and being executed.

\section{Discussion}

The results provide significant insights into SA Food and Beverage Manufacturing sector alignment with current global trends on COVID-19. The initial reliability tests indicate strong reliability of data. The data indicates a very strong alignment to most categories of COVID-19 responses as extracted from global literature. Essentially, SA FoodBev companies have responded in alignment to global literature trends in most areas, with some exceptions in HR and climate change.

Firstly, and most importantly, on the issue of COVID-19's impact, in the SA context, the analysis indicates a significant number of companies (12 of 106) would likely close with $65 \%$ of all companies predicting some future impact of COVID-19, aligning strongly with literature [8,36]. Companies need to structure finances to survive, access government grants, and other government incentives.

COVID-19 has a significant impact on operation, including supply chain. Although around 80\% of the companies source and distribute in SA, 50\% of those that source out of SA are seeking local sourcing due to supply chain interruptions. Centrally coordinated, digital, supply chain networks are a new global priority $[21,23,26,30]$ and SA companies agree about making digital supply chain skills a priority. SA companies prioritize adjustments in marketing strategies/digital marketing, and upskilling staff and emergency response teams as the top three resource-based mitigations aligning to significant evidence in literature $[15,20,27,33,34]$. SA companies are not focusing on an elastic workforce to mitigate resources constraints; this is in contrast to global considerations [33,34]. SA companies, most especially medium enterprises, seek technology as a solution with the link between technology and climate change not a fundamental. Specific to operations, the key resources and mitigation actions include social distancing, communication, and facilities reconfiguration. This is in support of the health and safety training required.

Skills infrastructure $[16,30]$ extends beyond the training cycle but extends into the operational space. The cross thematic analysis of all results indicates small and medium enterprises are most significantly impacted (70\% of all businesses closing down are small). Small businesses also forecast the highest future impact of COVID-19; this is as per literature [15,36] and anticipated government response. The particular impact on the meat industry is extracted in this study as per literature [6]. An additional and distinct new challenge reflected in the data is that small businesses experience significant additional administration bottlenecks; in the SA context, this seems to be due to the access of government support.

The cross functional analysis is based on various international best practices, as extracted. The first analysis relates to the skills required and delivery mechanisms, a Cronbach Alpha of 0.76 is calculated indicating strong reliability of all skills related questions. As per literature, 4IR skills is a priority and the adoption of 4IR tools to train is an expedited practice under COVID-19. A detailed analysis of the results indicates, in particular, skills required are digital training skills, online curriculum development, and assessment skills [37,38]. The support for setup of Virtual Reality (VR) simulators would provide for the plans to migrate to mixed methods. Infrastructure support is identified through literature [16] and confirmed in this study. Latchem [38] indicates a significant shift to mixed methods of skills development and the data extracted via this study strongly indicates the same with $83 \%$ of companies having already adopted or planning mixed methods skills delivery. Asynchronous learning is referenced in literature [37], and the cross functional results is in full agreement. The skills to optimize businesses to survive are essential. Foodbev company's sustainability is skills-based and the Foodbev SETA is most interested in the skills to focus on developing in order to achieve post COVID-19 sustainability.

An analysis of mitigation action provides for a Cronbach Alpha of 0.714 , indicating reliability between the various questions asked. SA companies are responding in alignment with international companies with regards to resources-based mitigation, adjusting marketing strategies, upskilling 
staff, emergency response teams, and new health and safety protocols. Operations-based mitigation include reconfiguration of facilities to mitigate the COVID-19 spread, increased communication, and transparency and social distancing at work as key actions.

\section{Conclusions}

This research paper identifies global literature relevant to COVID-19 specific to the Food and Beverage Manufacturing sector. A mixed methods approach is adopted to identify global literature and develop a literature relevant instrument to determine the SA contextualized response. The data and statistical analyses provides for insights on the alignment of SA's Food and Beverage Manufacturing Sector with global trends specific to COVID-19. The literature provides insights on current global responses in the Foodbev manufacturing sector. The themes are extracted and developed into a SA specific data instrument seeking SA Foodbev manufacturing companies' responses to COVID-19. A statistical analysis of the instrument data reveals Cronbach Alpha's mostly above 0.6, indicating reliability of the results. The results indicate a strong correlation of the SA Foodbev manufacturing sector in all key responses and mitigations as per global best practice.

Analysis of the results indicates around 10\% of companies specified potential closure due to COVID-19, with 65\% indicating future impacts due to COVID-19. This is a concerning initial indicator of COVID-19 impact on SME's in SA.

Key mitigation actions in SA include social distancing, communication, facilities reconfiguration and virtual working, this aligns strongly to international best practice. Mitigations not experienced in SA but actioned globally include human resources, specifically exploiting elastic workforces. With the onset of 4IR, technology adjustments are most significant in medium enterprises as a mitigation.

Global literature indicates significant supply chain impacts of COVID-19. SA supply chains are analyzed with $80 \%$ of SA companies dependent on the globe for inbound logistics, with $40 \%$ for outbound logistics. Forty-seven percent of companies found it difficult to access goods internationally. The most significant response to supply chain challenges being SA companies considering locally coordinated networks and digitalization of supply chains. This aligns strongly to international best practice.

SA Foodbev manufacturing companies have various mitigation measures in place, these align to international literature extractions with the following SA priority ranked responses: (1) adjusting marketing strategies, (2) upskilling staff, (3) emergency response teams, and (4) new health and safety protocols.

The SA specific government response, beyond lockdown support, is skills development to mitigate COVID-19 impact. The SETA is mandated to accelerate COVID-19 mitigation skills development. Literature indicates various global responses to skills development under COVID-19. The data analysis indicates a very strong and rapid response in alignment with global trends. Eighty-three percent of SA companies have already initiated some form of mixed methods skills response.

Priority skills are identified as well as infrastructure support in order to continue to deliver skills training to learners in the sector. Based on this study, the SETA has developed a strategy to support skills development in mitigation of COVID-19. These include digital skills, operational and training skills, supply chain skills, digital marketing skills, and Health Safety Environment (HSE) skills.

Author Contributions: This paper is researched and compiled by three authors with the following responsibilities. Conceptualization: A.T.; methodology: P.M.; A.T.; formal analysis: M.M.; A.T.; investigation: P.M., A.T.; data curation: M.M.; A.T.; writing: P.M.; M.M.; A.T.; original draft preparation: M.M.; A.T.; supervision: A.T. All authors have read and agreed to the published version of the manuscript.

Funding: This research was funded by the FoodBev manufacturing SETA in South Africa.

Acknowledgments: The research team seek to acknowledge the support by the University of Johannesburg for this research project.

Conflicts of Interest: The authors declare no conflict of interest. 


\section{References}

1. World Health Organization (WHO). Available online: https://www.who.int/ (accessed on 4 April 2020).

2. Johns Hopkins University. COVID-19 Dashboard by the Center for Systems Science and Engineering (CSSE) at Johns Hopkins University (JHU). Available online: https://coronavirus.jhu.edu/map.html (accessed on 3 September 2020).

3. National Institute for Comicable Diseases (NICD). Available online: https://www.nicd.ac.za/covid-19environmental-health-guidelines/ (accessed on 10 June 2002).

4. Rasool, H. Labour Market Series Part 2 COVID-19, Economy and Labour Market: Reforms for Post-School Education and Training. Available online: https://www.researchgate.net/publication/341423557_LABOUR_ MARKET_SERIES_PAPER_TWO_COVID-19_ECONOMY_AND_LABOUR_MARKET_REFORMS_FOR_ POST-SCHOOL_EDUCATION_AND_TRAINING (accessed on 10 June 2020).

5. Andersen, K.G.; Rambaut, A.; Lipkin, W.A.; Holmes, E.C.; Garry, R.F. The Proximal Origin of SARS-CoV-2. Nat. Med. 2020, 26, 45-452. [CrossRef] [PubMed]

6. Norje, C. Economic Impact of Covid-19 on the Meat Industry. Available online: https://sappo.org/economicimpact-of-covid-19-on-the-meat-industry/ (accessed on 30 May 2020).

7. Hyslop, G. Jumping on the Baking Boom: The Bread and Cookie Recipes Hitting the Headlines. Available online: https://www.bakeryandsnacks.com/Article/2020/05/14/Jumping-on-the-coronavirus-baking-boomThe-bread-and-cookie-recipes-hitting-the-headlines?utm_source=copyright\&utm_medium=OnSite\& utm_campaign=copyright (accessed on 4 June 2020).

8. Food And Agriculture Organization (FAO). COVID-19 and Smallholder Producers' Access to Markets 2020; Food and Agricultural Organization (FAO): Rome, Italy, 2020.

9. Citizan, T. Tiger Brands Says Sale of Listeriosis-Tainted Units Will not Affect Class Action. Available online: https://citizen.co.za/business/business-news/2343525/tiger-brands-says-sale-of-listeriosis-taintedunits-will-not-affect-class-action/ (accessed on 5 September 2020).

10. Larkin, P. Government Agree on Transportation of Beer. Available online: https://www.iol.co.za/businessreport/economy/sab-government-agree-on-transportation-of-beer-47820667 (accessed on 23 May 2020).

11. Reuters South African Shoppers Stock up on Booze as Sales Resume. Available online: https:/headtopics. com/us/south-african-shoppers-stock-up-on-booze-as-sales-resume-13401723 (accessed on 20 June 2020).

12. Hobbs, J.E. Food supply chains during the COVID-19 pandemic. Can. J. Agric. Econ. 2020, 68, 171-176. [CrossRef]

13. Food and Agricultural Organization (FAO). Summary of the Impacts of the COVID-19 Pandemic on the Fisheries and Aquaculture Sector, Addendum to the State of World Fisheries and Aquaculture 2020; Food and Agricultural Organization (FAO): Rome, Italy, 2020.

14. Food And Agriculture Organization (FAO). How Is COVID-19 Affecting the Fisheries and Aquaculture Food Systems; Food and Agricultural Organization (FAO): Rome, Italy, 2020.

15. Food And Agriculture Organization (FAO). COVID-19 and the Risk to Food Supply Chains: How to Respond? Food and Agricultural Organization (FAO): Rome, Italy, 2020.

16. Food And Agriculture Organization (FAO). FAO Rolls out Toolkit for Smart Policy Making during the COVID-19 Crisis 2020; Food and Agricultural Organization (FAO): Rome, Italy, 2020.

17. Falconer, T. Shifting Focus: How COVID-19 is Encouraging Diversification. Available online: https://www.ibisworld. com/industry-insider/coronavirus-insights/shifting-focus-how-covid-19-is-encouraging-diversification/ (accessed on 15 June 2020).

18. Helm, D. The Environmental Impacts of the Coronavirus. Environ. Resour. Econ. 2020, 76, 21-38. [CrossRef]

19. Rugani, B.; Caro, D. Impact of COVID-19 outbreak measures of lockdown on the Italian carbon footprint. Sci. Total Environ. 2020. [CrossRef]

20. Rosenbloom, D.; Markard, J. A COVID-19 recovery for climate. Science 2020, 368, 447. [CrossRef] [PubMed]

21. Choudhury, N.R. Food Sector Faces Multipronged Consequences of COVID-19 Outbreak. Available online: https: //www.globaltrademag.com/food-sector-faces-multipronged-consequences-of-covid-19-outbreak/ (accessed on 20 May 2020).

22. Aldaco, R.; Hoehn, D.; Laso, J.; Margallo, M.; Ruiz-Salmón, J.; Cristobal, J.; Kahhat, R.; Villanueva-Rey, P.; Bala, A.; Batlle-Bayer, L.; et al. Food waste management during the COVID-19 outbreak: A holistic climate, economic and nutritional approach. Sci. Total Environ. 2020, 742, 140524. [CrossRef] 
23. Weersink, A.; von Massow, M.; Mcdougall, B. Economic thoughts on the potential implications of COVID-19 on the Canadian dairy and poultry sectors. Can. J. Agric. Econ. 2020. [CrossRef]

24. Fitch Solutions. Economic and Suuply Chain Diversification in Asia in the Post Covid-19 Era. Available online: https://www.fitchsolutions.com/country-risk-sovereigns/economics/economic-and-supply-chaindiversification-asia-post-covid-19-era-26-05-2020 (accessed on 15 June 2020).

25. Hossain, S.T. Impacts of COVID-19 on the Agri-food Sector: Food Security Policies of Asian Productivity Organization Members. J. Agric. Sci. Sri Lanka 2020, 15, 116-132. [CrossRef]

26. Gemmill-Herren, B. Closing the circle: An agro ecological response to covid 19. Agric. Hum. Values 2020, 1-2. [CrossRef]

27. Preiss, P.V. Challenges facing the COVID-19 pandemic in Brazil: Lessons from short food supply systems. Agric. Hum. Values 2020, 37, 571-572. [CrossRef] [PubMed]

28. Fan, S. Preventing Global Food Security Crisis under COVID-19 Emergency. Available online: https://www. ifpri.org/blog/preventing-global-food-security-crisis-under-covid-19-emergency (accessed on 20 May 2020).

29. World Bank Group. Assessing the Economic Impact of COVID-19 and Policy Response in Sub Saharan Africa 2020; World Bank Group: Washington, DC, USA, 2020.

30. Galanakis, C.M. The Food Systems in the Era of the Coronavirus (COVID-19) Pandemic Crisis. Foods 2020, 9, 523. [CrossRef] [PubMed]

31. World Economic Forum. The Future of Jobs Report 2018; World Economic Forum: Cologny, Switzerland, 2018.

32. Kalpana, S.; Priyadarshini, S.R.; Maria Leena, M.; Moses, J.A.; Anandharamakrishnan, C. Intelligent packaging: Trends and applications in food systems. Trends Food Sci. Technol. 2019, 93, 145-157. [CrossRef]

33. Accenture. Coronavirus Business Economic Impact. Available online: https:/www.accenture.com/za-en/ about/company/coronavirus-supply-chain-impact (accessed on 15 May 2020).

34. Accenture. Productivity in Uncertain Times Through the Elastic Digital Workplace. Available online: https://www.accenture.com/mu-en/about/company/coronavirus-solution-elastic-digital-workplace (accessed on 15 May 2020).

35. Rizou, M.; Galanakis, I.M.; Aldawoud, T.M.S.; Galanakis, C.M. Safety of foods, food supply chain and environment within the COVID-19 pandemic. Trends Food Sci. Technol. 2020, 102, 293-299. [CrossRef] [PubMed]

36. Dyal, J.W.; Grant, M.P.; Broadwater, K.; Bjork, A.; Waltenburg, M.A.; Gibbins, J.D.; Hale, C.; Silver, M.; Fischer, M.; Steinberg, J.; et al. COVID-19 Among Workers in Meat and Poultry Processing Facilities-19 States, April 2020. Mmwr. Morb. Mortal. Wkly. Rep. 2020, 69, 557-561. [CrossRef] [PubMed]

37. Daniel, S.J. Education and the COVID-19 pandemic. Prospects 2020, 1-6. [CrossRef] [PubMed]

38. Latchem, C. Using ICTs and Blended Learning in Transforming TVET; United Nations Educational, Scientific and Cultural Organization: Paris, France, 2017.

39. Verawardina, U.; Asnur, L.; Lubis, A.L.; Hendriyani, Y.; Ramadhani, D.; Dewi, I.P.; Darni, R.; Betri, T.J.; Susanti, W.; Sriwahyuni, T. Reviewing online learning facing the Covid-19 outbreak. Talent Dev. Excell. Spec. Issue 2020, 12, 385-392.

Publisher's Note: MDPI stays neutral with regard to jurisdictional claims in published maps and institutional affiliations.

(C) 2020 by the authors. Licensee MDPI, Basel, Switzerland. This article is an open access article distributed under the terms and conditions of the Creative Commons Attribution (CC BY) license (http://creativecommons.org/licenses/by/4.0/). 